


$\square$
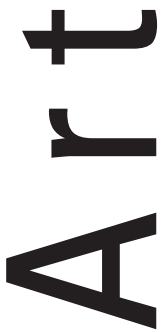


\title{
Oscilação das chuvas na porção centro oeste do estado de Mato Grosso, entre os anos de 1996 a 2001
}

\author{
Oscillations des pluies dans la portion centre-ouest de l'etat de Mato Grosso, entre les annees 1996 \\ et 2001.
}

\author{
Romário Rosa de Sousa Universidade Federal de Mato Grosso \\ romarioufg@yahoo.com.br \\ Luiz Gonzaga Toledo - Universidade Federal de Mato Grosso \\ romarioufg@yahoo.com.br
}

Doroty Queiroz Topanotti - Universidade Federal de Mato Grosso

romarioufg@yahoo.com.br

\section{Resumo}

0 presente trabalho analisou a oscilação das chuvas anuais ocorridas na porção Centro-Oeste do Estado de Mato Grosso entre os anos de 1996 a 2001, identificando os municípios que tiveram mais e menos acúmulos pluviométricos, com posterior geração de mapas de isoietas através de técnicas de interpolação no programa de Surfer versão 8, da Golden Software Inc. Os maiores valores pluviométricos foram registrados nos anos de 1998 e 1996, com somas de 2300 a $2350 \mathrm{~mm}$, abrangendo os municípios de Comodoro, Nova Lacerda, Campos de Júlio, Sapezal e Tangará da Serra. Já no ano de 1999, registrou-se menor valor pluviométrico com $1900 \mathrm{~mm}$, nos municípios de Comodoro e Nova Lacerda. A variabilidade pluviométrica ocorreu ao longo dos seis anos de estudo, período em que a chuva foi bem irregular, durante todos os anos analisados. Com os resultados obtidos das análises dos mapas de isoietas de 1996 a 2001, identificou-se que preferencialmente, as chuvas ocorreram em maior quantidade nas porções Oeste e Norte, sendo que as menores quantidades chuvosas registraram-se nas porções Leste e Sul.

Palavras-chave: Oscilação, chuva, precipitação, variabilidade, distribuição.

\section{Résumé}

Le présent travail a analisé l'oscillation des pluies annuelles qui ont été tombées dans la portion Centre-Ouest de l'Etat de Mato Grosso, entre les années de 1996 à 2001, identifiant les districts qui ont été plus ou moins des accumules pluviométriques, avec postéurieure génération des cartes des isoyètes à travers des téchniques d'interpolation dans le programme Surfer, version 8, de la Golden Software Inc. Les plus grandes valeurs pluviométriques ont été enrégistrées dans l'années 1998 à 1996, avec des additions de 2300 à 2350mm, renfermant les districts de Comodoro, Nova Lacerda, Campos de Júlio, Sapezal et Tangará da Serra. Néanmoins dans l'année 1999 nous l'avons enregistrée une petite valeur pluviométrique avec $1900 \mathrm{~mm}$, dans les districts de Comodoro et Nova Lacerda. La variabilité pluviométrique a eu lieu le long des 6 anées d'études, où la pluie a été bien irregulière, pendant toutes les années analysées. Avec les résultats obtenus des analyses des cartes des isoyètes de 1996 à 2001, nous avons identifié que préférentiellement, les pluies ont tombées en majeure quantité dans les portions Ouest et Nord, étant donnée, que les mineures quantités pluvieuses ont été enrégistrées dans les portions Est et Sud.

Mots clés: Oscillation, pluies, précipitation, variabilité, distribution.

Boletim Goiano de Geografia $\quad$ Goiânia - Goiás - Brasil

v. 27

ก. 3

p. $71-89$

jul. / dez. 



\section{Introdução}

No mundo atual, existem milhões de pessoas que sofrem com os efeitos climáticos, especialmente aquelas das regiões semi-áridas, onde muitos não possuem recursos que permitam o uso de tecnologia capaz de superar as limitações predominantes 2004). Entre os diversos meios necessários à vida, o clima tem características fundamentais.

Durante os primeiros tempos históricos, o testemunho climático consistia em lendas. As compreensões do homem sobre os fenômenos do tempo atmosférico eram controladas pelos deuses, até por volta do quinto século antes de Cristo, quando os gregos começaram a fazer observações sistemáticas dos fenômenos meteorológicos (2002).

Vivemos numa época de grandes transformações ambientais, na qual as alternâncias de períodos chuvosos e secos assumem proporções de calamidade. Segundo Sant'Anna Neto (2000), em função da intensidade da ocupação humana, quer nas atividades agrárias, quer nas aglomerações urbanas, torna-se inegável o controle das intervenções de natureza humana no meio-ambiente

A variabilidade pluviométrica e suas relativas quantidades de precipitações, com seus regimes sazonais ou diários, distribuição temporal e as intensidades de chuvas individuais (volume/duração), são algumas das características que afetam direta ou indiretamente a população, a economia e o meio natural.

A distribuição variável da pluviosidade anual apresenta um risco ao produtor agrícola, podendo retardar a expansão da área cultivada dos Cerrados, (1982), uma vez que são importantes, não somente o total das chuvas, mas também a sua distribuição durante os estágios de desenvolvimento das culturas.

O objetivo principal deste trabalho foi analisar a oscilação e a variabilidade das chuvas anuais ocorrida na porção Centro-Oeste do Estado de Mato Grosso, entre os anos de 1996 a 2001.

\section{Localização e acesso}

O Estado de Mato Grosso está localizado entre as coordenadas geográficas de latitudes $7^{\circ}$ a $18^{\circ}$ sul e longitudes $50^{\circ}$ a $62^{\circ}$ oeste de Greenwich. As altitudes variam de 100 a 1200 metros, no centro do Continente Sul Americano. 
A área delimitada para esses estudos, dentro do estado está compreendida entre, as coordenadas geográficas de latitudes $10^{\circ}$ a $14^{\circ}$ sul e longitudes $60^{\circ}$ e $55^{\circ}$ oeste de Greenwich, situando-se aproximadamente $300 \mathrm{~km}$ da cidade de Cuiabá, capital do estado (Figura 1).

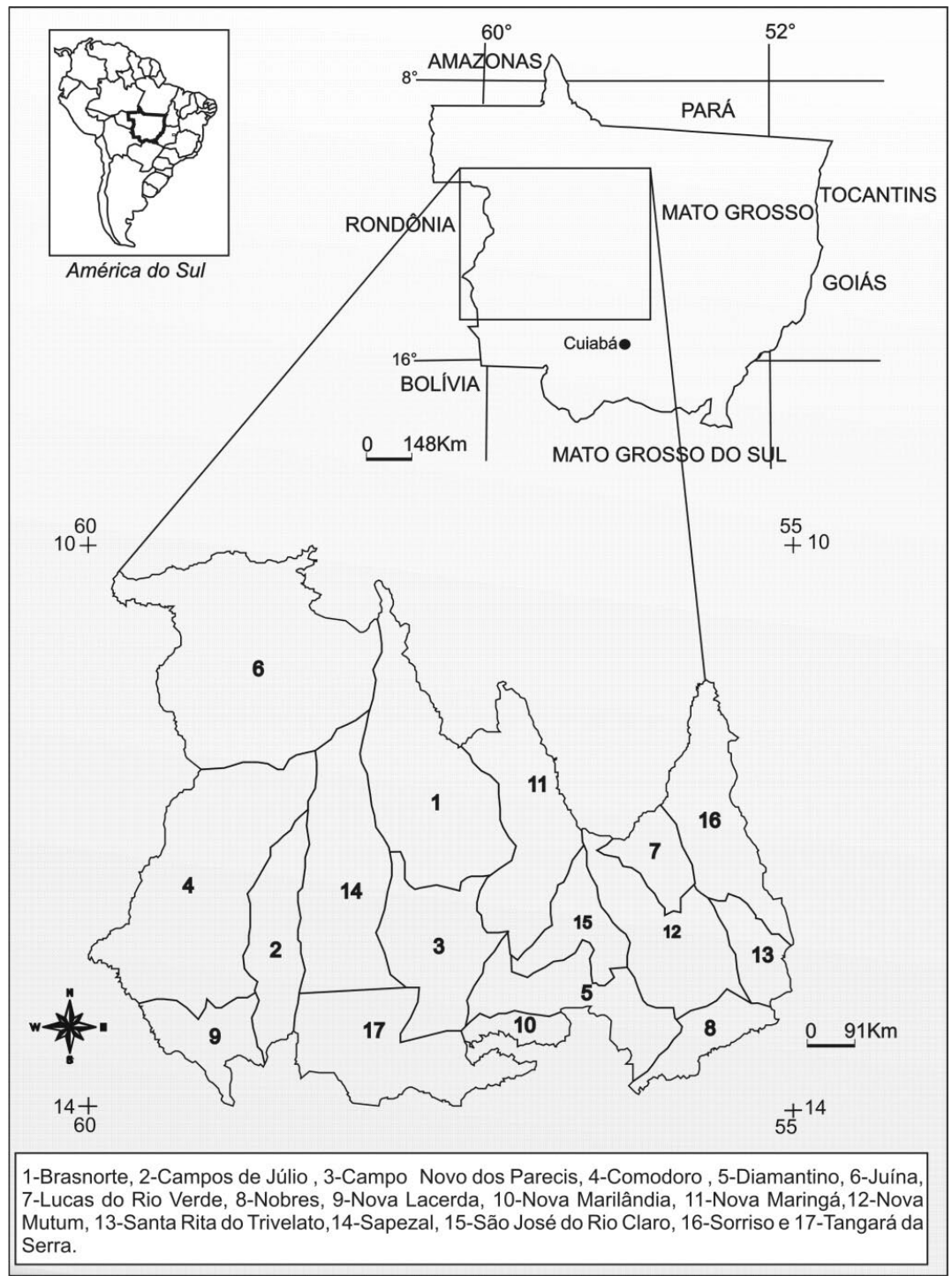

Figura 1 - Mapa de localização da área de estudos no Estado de Mato Grosso. 
O acesso à área de estudo é possibilitado através das rodovias federais BR'S - 070, 163, 174 e 364, e pelas rodovias estaduais MT'S - 160, 170, 220, 235, 319, 325, 338, 340 e 358 .

Dessa forma, constituem a área de estudo um total de 17 municípios: 1-Brasnorte, 2-Campos de Júlio, 3-Campo Novo dos Parecis, 4-Comodoro, 5-Diamantino, 6-Juína, 7-Lucas do Rio Verde, 8-Nobres, 9-Nova Lacerda, 10-Nova Marilândia, 11-Nova Maringá, 12-Nova Mutum, 13-Santa Rita do Trivelato,14-Sapezal, 15-São José do Rio Claro, 16-Sorriso e 17-Tangará da Serra, numerados em ordem alfabética.

\section{Material e métodos}

Os trabalhos metodológicos foram propostos por Matheron (1965), apud Assad et al. (1994), com a realização procedimentos teóricos e práticos, baseando-se nos dados cedidos pela Agência Nacional de Águas (ANA), e do $9^{\circ}$ Distrito de Meteorologia de Mato Grosso e Rondônia - Instituto Nacional de Meteorologia - DISME/INMET, com sede em Várzea Grande, MT, somando-se assim 14 postos pluviométricos.

Os dados analisados provêm de postos coletores fixados na área de estudo, e de estações convencionais e automáticas, onde os mesmos foram organizados primeiramente, sob a forma de arquivos ASCII, de onde foram extraídos os totais anuais, e transportados para planilha eletrônica, para a realização do recobrimento de falha, pelo método de ponderação regional, usando-se a seguinte equação: ; onde:

- yc é a precipitação do Posto Y a ser estimada; - x1, x2 e x3= as precipitações correspondentes ao ano que se desejou preencher, a falha observada em três postos de coletas vizinhos;

- ym a precipitação média do posto Y; - xm1, xm2, xm3= as precipitações médias nos três postos de coletas circunvizinhos.

Após o preenchimento de falhas, quando necessário, realizou-se a regressão linear múltipla, para se verificar e ter consistência dos dados utilizando-se a equação: yc x2i + x n1 + na; onde:

- $\mathrm{n}=$ o número de postos considerados, ao, a1, $\cdots$;

- na $=$ os coeficientes a serem estimados e 
Xli, $\mathrm{x} 2 \mathrm{i}, \cdots, \mathrm{xni}=$ as observações correspondentes registradas nos postos vizinhos.

Posteriormente, os valores foram organizados de acordo com as coordenadas geográficas, ou seja:

- a Longitude X representa a distância leste de uma marca de nível medida dentro de $[\mathrm{m}]$;

- a Latitude Y, representa o norte da distância de uma marca de nível medida também dentro de $[\mathrm{m}] \mathrm{e}$

$\mathrm{Z}$ representa a intensidade da precipitação medida dentro de [cm/hr], que corresponde aos valores dos dados hidroclimáticos a serem interpolados, tendo como resultado final a geração de mapas de isoietas no programa de Surfer versão 8, da Golden Software Inc.

Seguindo as orientações de Sousa et al. (2006), também foi definido o intervalo médio de $150 \mathrm{~mm}$, entre um valor e outro de quantidades em milímetros de chuva, o que possibilitou uma melhor padronização e interpretação dos mapas.

A área de estudos está representada por três unidades geomorfológicas, conhecidas como: Depressão Interplanáltica da Amazônia Meridional, Planalto Residual do Norte do Mato Grosso e Planalto dos Parecís (1980).

A Depressão Interplanáltica da Amazônia Meridional se descortina através de um corredor constituído por rochas pertencentes às unidades litodêmicas Complexo Xingu (et al. 1974, 1980) e Granitóide Paranaíta (Bittencourt Rosa et al. 1997), apresentando-se em longo processo de exposição e arrasamento, esculpindo relevos via de regra, planos com elevações esparsas, onde as cotas variam, entre 150 a 180 metros.

A Depressão Sul Amazônica está contida nos "limites" de atuação dos sistemas equatoriais, onde a oferta pluvial em um ano, é de 2000 a $2400 \mathrm{~mm}$ (2002).

O Planalto Residual do Norte do Mato Grosso corresponde à unidade geomorfológica representada pelas Serras do Cachimbo e Caiabís. As altitudes variam entre 400 a 520 metros, e se configuram em interflúvios que formam os modelados dos relevos residuais embutidos na Depressão Interplanáltica da Amazônia Meridional.

O Planalto dos Parecis, primeiramente estudado por Derby (1895), está compartimentado: pelo Planalto Dissecado dos Parecis e pela Chapada dos Parecis. O Planalto Dissecado dos Parecia corresponde à unidade geomorfológica que abrange uma expressiva área de planaltos distribuída através 
de terrenos paleozóicos e cenozóicos, constituindo o divisor de águas entre, as Bacias Platina e Amazônica, cujo relevo se apresenta segundo, Werle \& Alves da Silva (1996), dissecado com formas tabulares de grande amplitude, elevações residuais com cimos planos, bordejadas por escarpas que constituem patamares estruturais escalonados. A pluviometria anual é de 1000 a $2000 \mathrm{~mm}$.

A Chapada dos Parecis abrange, uma expressiva área aplainada, com altitudes que atingem os 550 metros, recoberta por um depósito de Cobertura Detrito-Laterítica de idade Tércio-Quaternária. A variação pluviométrica é de 1400 a $2000 \mathrm{~mm}$ ao ano.

O Planalto dos Parecis é o grande divisor de águas entre a Bacia Amazônica ao Norte e a Bacia Platina ao Sul. Esta vasta área, posicionada entre a zona intertropical (Floresta amazônica), savanas tropicais (Cerrado) e a Depressão Continental do Chaco (Pantanal) ao Sul, sob o ponto de vista do quadro natural, possui características marcantes. Desta forma, o Estado de Mato Grosso encontra-se numa área de transição entre a atuação dos fluxos Tropical, Equatorial e Extratropical, os quais produzem variações em tipos de tempo bem característicos desta região.

A cobertura vegetal de floresta ainda é presente, principalmente, nos setores ao norte das bacias hidrográficas dos rios Juruena e Teles Pires, destacando-se a Floresta Semidecidual Dossel Emergente, que corresponde, segundo Amaral et al. (1982) e Bittencourt Rosa et al. (2002), a uma única formação vegetal que corresponde à floresta aluvial com dossel emergente, encontrada nas planícies e terraços aluviais, notadamente em terrenos terciários e quaternários recobertos por Neossolos Quartzarênicos Hidromórficos (EMBRAPA, 1999), às vezes inundáveis.

\section{Resultados e discussão}

A interpretação e análise dos sistemas atmosféricos na América do Sul é apresentada por Monteiro (1964, 1969), citado por Sette (2002), modificado, a partir de estudos de estudos de Serra \& Rattsbonna (1942). Neste esquema, os principais sistemas atmosféricos que atuam na região central do Brasil são: Massa Tropical Continental (MTc); Massa Equatorial Continental (MEc); Massa Tropical Atlântica (MTa); Massa Equatorial Atlântica (MEa); Massa Equatorial do Atlântico Norte (MEn); Massa Polar Atlântica (MPa); Frente Polar Atlântica (FPA) e Zona de Convergência Intertropical (ZCIT). 
O pioneiro em realizar uma caracterização da circulação de superfície para o antigo Estado do Mato Grosso (MT e MS) foi Serra (1948), que descreveu o ritmo sazonal dos movimentos da baixa atmosfera para as quatro estações do ano. Posteriormente, Nimer (1979), com base nos trabalhos de Serra (1948), realizou um estudo, no qual ressalta dois fatores geográficos, ou seja, o relevo e a latitude como responsáveis da diversificação térmica. Por outro lado, estes estudiosos colocam o mecanismo atmosférico determinante na “marcha estacional de precipitação pluviométrica”, que é máxima no verão e mínima no inverno, adequando uma uniformidade regional.

De acordo com a classificação climática, para as grandes linhas do clima de Durand Dastès (1968), modificada por Estienne \& Godard (1970), as temperaturas, localmente, podem variar, entre $24^{\circ}$ a $36^{\circ} \mathrm{C}$, durante a estação chuvosa, cuja pluviometria média regional é de $1.700 \mathrm{~mm}$. A umidade relativa do ar é variável e durante a estação das chuvas pode atingir a faixa dos $80 \%$, enquanto que na estação seca ela é de aproximadamente $50 \%$.

O sistema de circulação atmosférica na região Centro-Oeste é constituído por ventos que sopram a Oeste (IT) - Linha de Instabilidades Tropicais, Norte (CIT7) - Convergência Inter-tropical e Sul (FP) - Anticiclone Polar e Frente Polar. Desta forma no entender de Nimer (1979), a pluviosidade em Mato Grosso se deve, exclusivamente, ao regime de circulação atmosférica

De acordo com classificação climática elaborada por Sette \& Tarifa (2000), os sistemas atmosféricos que atuam em Mato Grosso são: Zona de Convergência Intertropical (ZCIT), Sistema Equatorial, Sistema Tropical Continental (STC), Sistema Tropical Atlântico (STA), Sistema Polar Atlântico (SPA). Zona de Convergência do Atlântico Sul (ZCAS). Desta forma, os sistemas atmosféricos atuantes na área de estudo são: Sistema Amazônico - SAM, Tropical Continental com Subsidência - TCS, Tropical Continental Convectivo - TCC, Sistema Polar Continentalizado - SPC, Sistema Tropical Atlântico Continentalizado - TAC e Zona de Convergência do Atlântico Sul - ZCAS.

A média anual da precipitação de um núcleo mais chuvoso ao Norte de Mato Grosso pode atingir valores superiores a $2750 \mathrm{~mm}$ (Nimer, 1979).

Tais valores decrescem nas direções leste, oeste e sul do estado, resultando então, numa precipitação, que se distribui de forma irregular, durante todo o ano, sendo o verão o seu máximo e, o inverno o seu mínimo, sendo que $70 \%$ do total de chuvas acumuladas, durante o ano se precipitam entre novembro a março meses, correspondentes ao verão. Durante esse trimestre, a precipitação chega atingir 45\% até 55\% do total anual das chuvas (1989). 
Do ponto de vista agro-climatológico, a região dos cerrados está sujeita ao regime de secas, dentro da estação chuvosa, a qual pode persistir de duas a, três semanas e atingir até um mês ou mais sem chuvas, fenômeno é denominado de veranico. (et al. 1994). O fenômeno veranico é considerado por Casarim (1983) como uma causa dos bloqueios de grande escala no escoamento atmosférico. a partir desse ponto de vista, o mecanismo do veranico pode estar associado aos deslocamentos da zona de convergência tropical e ao fenômeno "El Nino", diretamente relacionado com o aumento da temperatura do Oceano Pacífico.

Em contrapartida, o inverno é extremamente seco, e é nessa época que ás chuvas são raras, com precipitações de quatro a cinco dias nos meses de junho, julho e agosto, concentrando totais muito baixos, entre 20 e 80 mm de pluviosidade, fazendo com que a região fique na dependência quase exclusiva das chuvas frontais, que são proporcionadas pela passagem de frentes polares trazidas do sul pelo anticiclone polar (FK). Desta maneira, as ocorrências de chuvas no extremo norte do Estado de Mato Grosso são conseqüências do sistema de circulação perturbada de oeste (IT) (Tarifa et al. 2006).

O trimestre de setembro a novembro é caracterizado por temperaturas extremamente aquecidas no equinócio de primavera (Outubro-Novembro), com pouca ocorrência de precipitações e o aumento gradativo do regime pluviométrico só vai acontecer com o final da primavera, coincidindo com o início do verão no mês de dezembro (et al. 1994).

O Vale do Araguaia é o que apresenta os menores totais pluviométricos com (10 a $20 \mathrm{~mm})$.

Dessa forma, segundo (Tarifa et al. 2006), as áreas de maior pluviosidade correspondem ao extremo norte e noroeste do estado e, nestas áreas os totais médios anuais variam entre 2100 a $2500 \mathrm{~mm}$.

Diante da série estudada nesses seis (06) anos, notou-se que a pluviometria comportou-se de forma bem variável. Apenas nos ano de 1998 e 1996, a soma da chuva acumulada foi a 2300 a $2350 \mathrm{~mm}$, sendo que nos demais anos, a soma total ficou sempre abaixo da média estipulada por Tarifa et al. (2006).

As intensidades pluviométricas registradas no ano de 1996, Figura 2, de maior representatividade na porção oeste ocorreram nos municípios de Comodoro, Campos de Júlio, Sapezal e Tangará da Serra com 2300 mm. Em direção ao norte e ao sul, o segundo maior valor anual foi de $2150 \mathrm{~mm}$, que ocorreu nos municípios de Juína, Brasnorte, Nova Lacerda, Nova Marilândia e Campo Novo dos Parecis. 
Dessa forma, na porção Leste, os menores valores pluviométricos foram quantificados de 1850 a $1400 \mathrm{~mm}$, que estiveram presentes nos municípios de Nova Maringá, São José do Rio Claro, Diamantino, Lucas do Rio Verde, Nova Mutum, Norbres, Sorriso e Santa Rita do Trivelato.

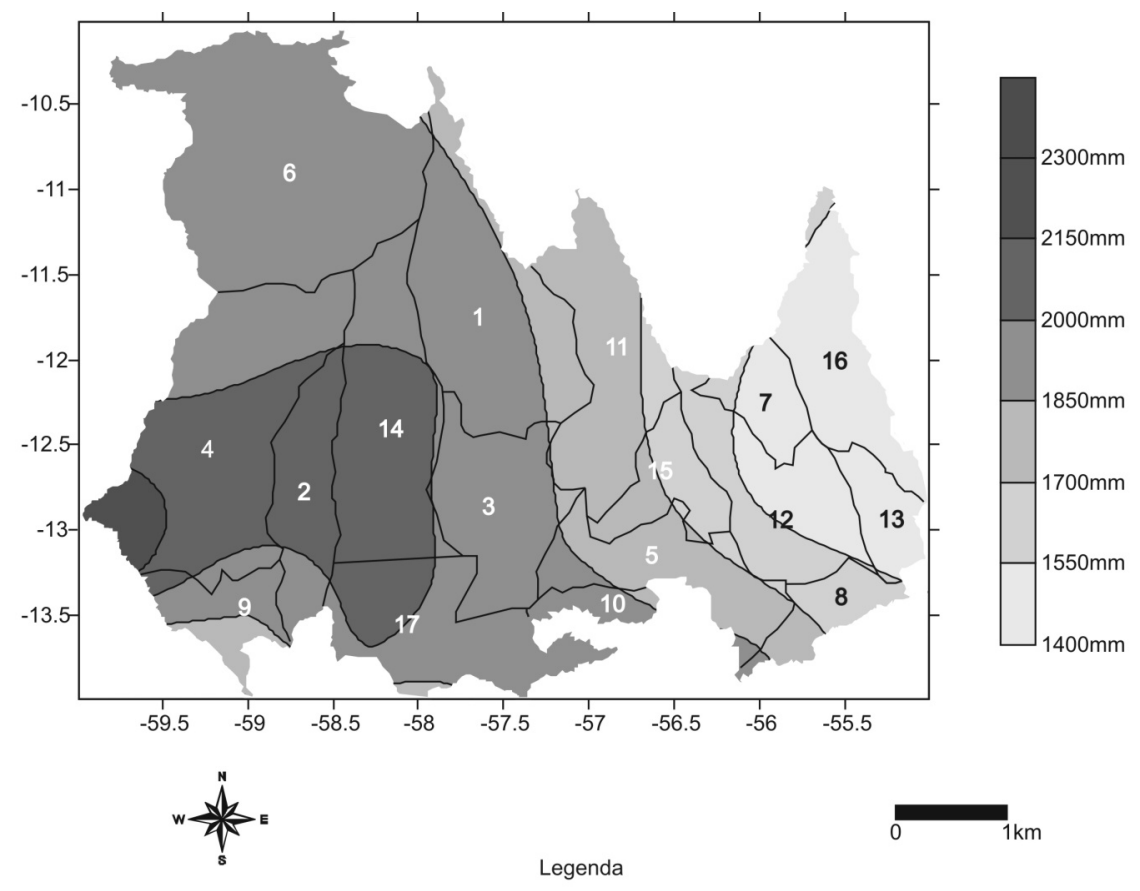

1-Brasnorte, 2-Campos de Júlio , 3-Campo Novo dos Parecis, 4-Comodoro , 5-Diamantino, 6-Juína, 7 Lucas do Rio Verde, 8-Nobres, 9-Nova Lacerda, 10-Nova Marilândia, 11-Nova Maringá,12-Nova Mutum, 13-Santa Rita do Trivelato,14-Sapezal, 15-São José do Rio Claro, 16-Sorriso e 17-Tangará da Serra.

Figura 2 - Mapa pluviométrico de 1996.

Os menores valores pluviométricos identificados no ano de 1997, Figura 3, com 1520mm, foram somados nos municípios de Nobres, Nova Mutum, Santa Rita do Trivelato e Sorriso, sendo que estes estão situados na porção Leste da área de estudo. Mediante a isso o segundo menor valor de $1670 \mathrm{~mm}$, foi observados nas porções Norte e Oeste, sendo que a espacialização está sobre os municípios de Juína, Comodoro, Nova Lacerda, Nova Maringá, Diamantino, Nova Marilândia, São José do Rio Claro e Lucas do Rio Verde.

Ainda averiguando a Figura 3, nota-se, perfeitamente que a variabilidade das chuvas aconteceu de forma bem expressiva, sendo que o núcleo 
mais chuvoso, com a maior quantidade, ocorreu no município de Tangará da Serra com 1970 mm. Nos municípios de Campos de Júlio, Sapezal e Campo Novo dos Parecis, a chuva ocorreu em menor quantidade, com $1820 \mathrm{~mm}$, sendo que estes municípios encontram-se na porção sul da área de estudo. Com isso, é importante ressaltarmos que houve um destaque chuvoso da ordem de 1820 mm na Figura 3, localizado no extremo sudoeste da área de estudo abrangendo parte dos municípios de Comodoro e Nova Lacerda.

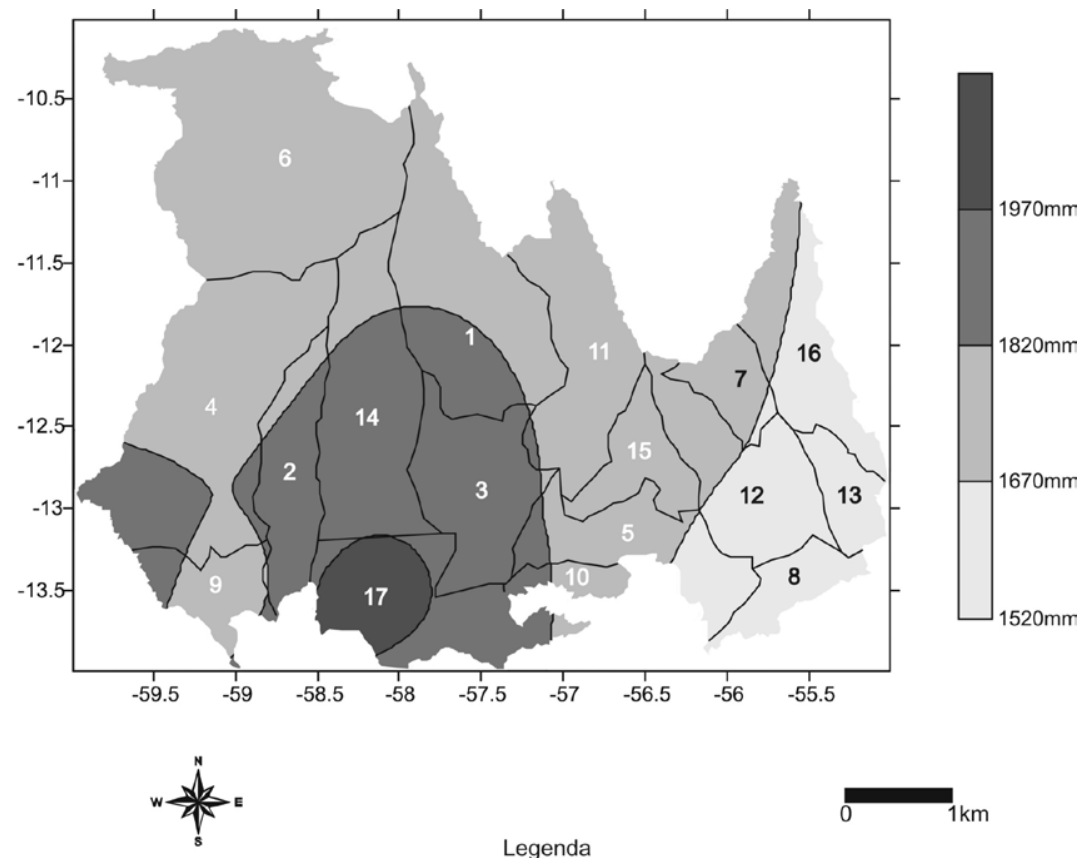

1-Brasnorte, 2-Campos de Júlio , 3-Campo Novo dos Parecis, 4-Comodoro , 5-Diamantino, 6-Juína, 7Lucas do Rio Verde, 8-Nobres, 9-Nova Lacerda, 10-Nova Marilândia, 11-Nova Maringá,12-Nova Mutum, 13-Santa Rita do Trivelato,14-Sapezal, 15-São José do Rio Claro, 16-Sorriso e 17-Tangará da Serra.

Figura 3 - Mapa pluviométrico de 1997.

A oscilação pluviométrica observada na Figura 4, referente ao ano de 1998, foi somada com a maior quantidade na porção oeste sobre os municípios de Comodoro, Nova Lacerda e Campos de Júlio com registros de 2050 até $2350 \mathrm{~mm}$. Enquanto isso, nas porções norte e na leste, a variação das chuvas foi de 1450 a1900 mm. A espacialização nos municípios de Juína, Brasnorte, Sapezal, Tangará da Serra, Campo Novo dos Parecis, Nova 
Maringá, São José do Rio Claro, Diamantino, Nova Marilândia, Lucas do Rio Verde, e no extremo norte do município de Sorriso, demonstra a atuação pluviométrica na área de estudo.

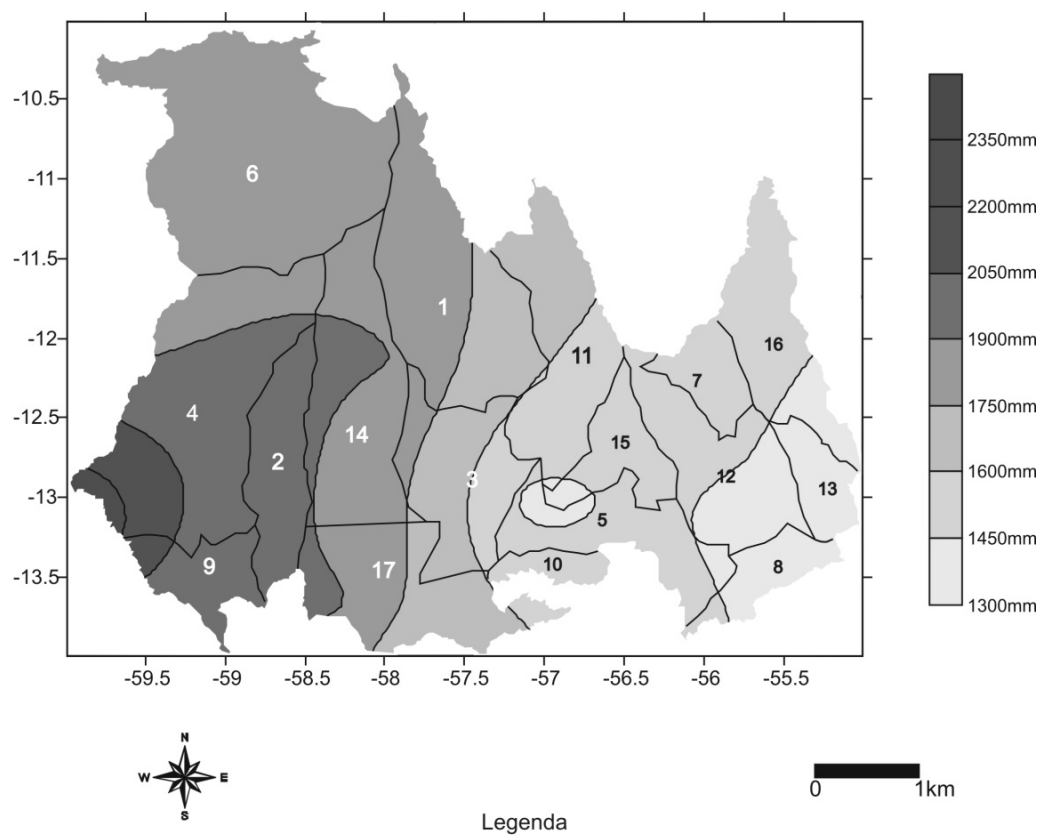

1-Brasnorte, 2-Campos de Júlio , 3-Campo Novo dos Parecis, 4-Comodoro , 5-Diamantino, 6-Juína, 7 Lucas do Rio Verde, 8-Nobres, 9-Nova Lacerda, 10-Nova Marilândia, 11-Nova Maringá,12-Nova Mutum, 13-Santa Rita do Trivelato,14-Sapezal, 15-São José do Rio Claro, 16-Sorriso e 17-Tangará da Serra.

Figura 4 - Mtapa pluviométrico de 1998.

Neste contexto, diante do exposto sobre a Figura 4, evidenciou-se que no extremo sul do município de Sorriso e nos municípios de Nova Mutum, Nobres e Santa do Trivelato, houve o menor registro pluviométrico durante todo o ano de 1998, com uma soma de 1300mm.

No ano de 1999, a variação das chuvas também ocorreu de forma bem expressiva. Novamente o maior valor pluviométrico aconteceu na porção oeste e mais precisamente, no município de Comodoro, com $1900 \mathrm{~mm}$. Já em direção à porção norte, com $1600 \mathrm{~mm}$, a chuva atuou em quantidade inferior.sobre os municípios de Juína, Campos de Júlio, Nova Lacerda, Sapezal e Brasnorte. 
Desta forma, na porção sul da área de estudos, se estendeu uma faixa chuvosa até as porções norte e leste com registro pluviométrico de $1450 \mathrm{~mm}$, abrangendo os municípios de Campo Novo dos Parecis, Tangará da Serra e o extremo sul dos municípios de Nova Marilândia, Daiamantino, e Nobres.

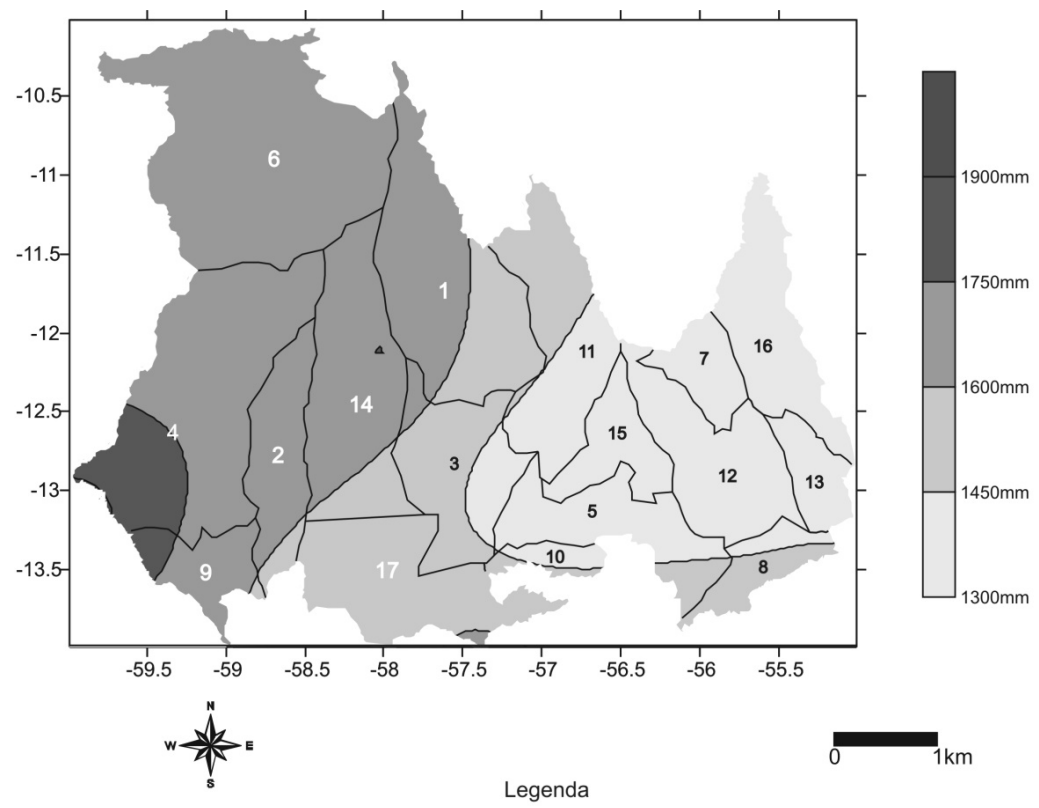

1-Brasnorte, 2-Campos de Júlio , 3-Campo Novo dos Parecis, 4-Comodoro , 5-Diamantino, 6-Juína, 7 Lucas do Rio Verde, 8-Nobres, 9-Nova Lacerda, 10-Nova Marilândia, 11-Nova Maringá,12-Nova Mutum, 13-Santa Rita do Trivelato,14-Sapezal, 15-São José do Rio Claro, 16-Sorriso e 17-Tangará da Serra.

Figura 5 - Mapa pluviométrico de 1999.

Em toda a porção leste da área de estudos representada na Figura 5, foi averiguado o menor acúmulo pluviométrico no ano de 1999, com um valor de 1300 mm nos municípios de Nova Marilândia, Nova Maringá, Diamantino, Nova Mutum, Lucas do Rio Verde, Sorriso, Santa Rita do Trivelato, e no extremo norte do município de Nobres.

O menor valor quantificado de chuva ocorrido no ano 2000 está representado na Figura 6, o qual esteve presente na porção sul, e em parte das porções norte e leste da área de estudos sobre os municípios de Brasnorte, Nova Maringá, São José do Rio Claro, Lucas do Rio Verde, Campo Novo dos Parecis, Nova Marilândia, Diamantino, Nova Mutum, Santa Rita do Trivela- 
to e Nobres. Em contrapartida, no extremo norte do município de Sorriso, a variação pluviométrica foi de $1600 \mathrm{~mm}$.

Também um valor de $1600 \mathrm{~mm}$ ocorreu em parte das porções norte e sul nos municípios de Sapezal, Campos de Júlio, Tangará da Serra e em parte do município de Juína.

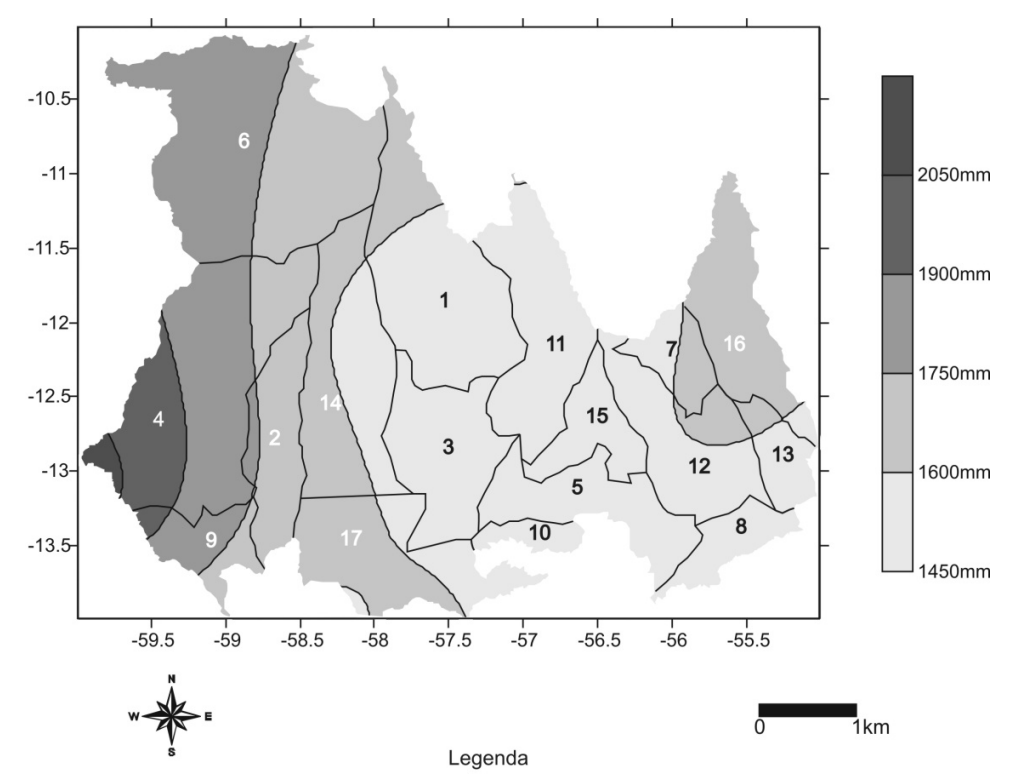

1-Brasnorte, 2-Campos de Júlio , 3-Campo Novo dos Parecis, 4-Comodoro , 5-Diamantino, 6-Juína, 7Lucas do Rio Verde, 8-Nobres, 9-Nova Lacerda, 10-Nova Marilândia, 11-Nova Maringá, 12-Nova Mutum 13-Santa Rita do Trivelato,14-Sapezal, 15-São José do Rio Claro, 16-Sorriso e 17-Tangará da Serra.

Figura 6 - Mapa pluviométrico de 2000.

Com isso, os maiores valores de 1750 até $2050 \mathrm{~mm}$ estiveram sobre os municípios de Comodoro, Nova Lacerda e no extremo oeste do município de Juína.

As intensidades pluviométricas averiguadas no ano 2001, demonstradas na Figura 7, foram em maior quantidade ocorreram no extremo oeste e norte da área de estudo com registro de $2200 \mathrm{~mm}$, no município de Comodoro, e de 1750 até 2050 mm, nos municípios de Juína, Campos de Júlio, Nova Lacerda e Sapezal.

Diante da variabilidade das chuvas ocorrida no ano de 2001, observou-se que, na porção sul, aconteceu uma faixa chuvosa em direção à porção 
norte, onde a somatória pluviométrica foi de $1600 \mathrm{~mm}$, nos municípios de Brasnorte, Campo Novo dos Parecis, Nova Maringá, Diamantino e Nova Marilândia. Na porção leste da área de estudo, nos respectivos municípios de São José do Rio Claro, Juína, Nova Mutum, Nobres, Santa Rita do Trivelato, e Sorriso, ocorreu a menor soma registrada com $1450 \mathrm{~mm}$.

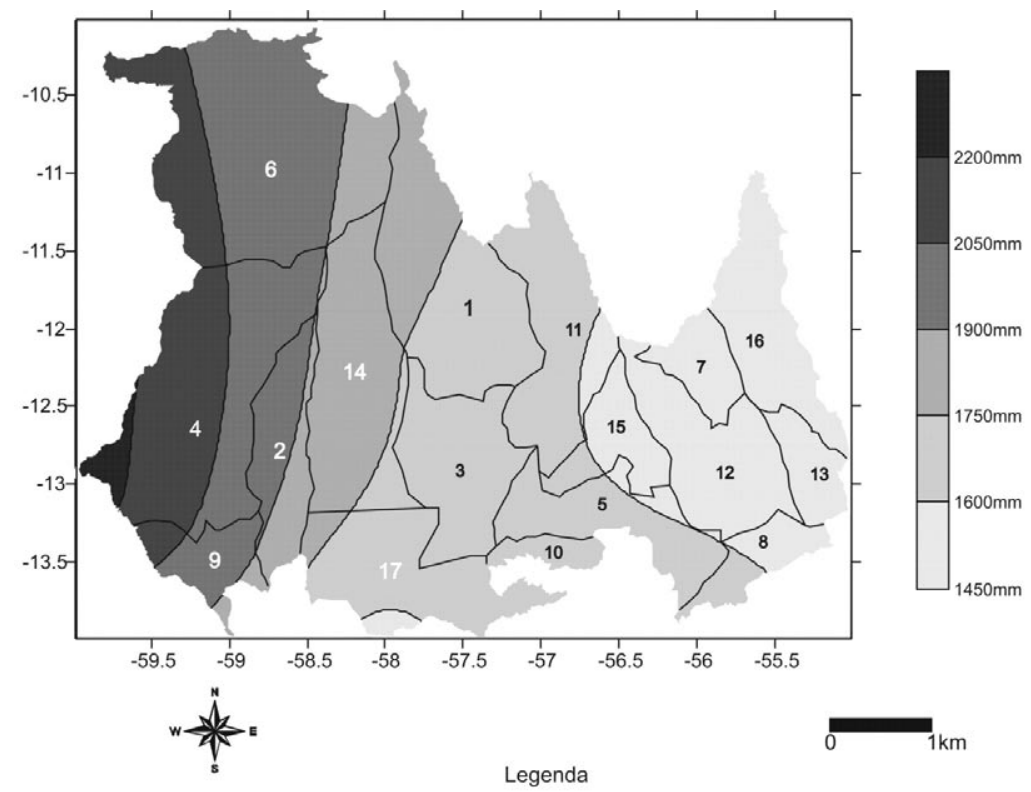

1-Brasnorte, 2-Campos de Júlio ,3-Campo Novo dos Parecis, 4-Comodoro , 5-Diamantino, 6-Juina, 7 Lucas do Rio Verde, 8-Nobres, 9-Nova Lacerda, 10-Nova Marilândia, 11-Nova Maringá,12-Nova Mutum, 13-Santa Rita do Trivelato,14-Sapezal, 15-São José do Rio Claro, 16-Sorriso e 17-Tangará da Serra.

Figura 7 - Mapa pluviométrico de 2001.

Segundo Assad \& Sano (1993), o clima do Planalto Central é caracterizado por uma estação seca bem característica e outra bem chuvosa. Este fator pode ser, de uma maneira geral, generalizado para toda a Região do Centro-Oeste do Brasil, apresentando assim uma irregularidade pluviométrica, o que acarreta a variabilidade pluviométrica, espacial e/ou temporal, tal acontecimento pode ocasionar efeitos danosos a solos desprotegidos de cobertura vegetal.

Portanto, com relação ao grande domínio morfoclimático e fitogeográfico dos cerrados, espera-se que nós, homens modernos, tenhamos um pouco mais de cuidados com o meio-ambiente, e já devemos começar a pensar numa 
possível escassez hídrica, haja vista que, na atualidade, estamos vivendo uma nova face da ocupação econômica dos cerrados com as nossas atividades urbanas e agrícolas importantes, como o agronegócio (Ab’Saber, 2003).

\section{Considerações finas}

Observando-se os mapas de isoietas de 1996 a 2001, identificou-se que, preferencialmente, as chuvas ocorreram em maior quantidade nas porções oeste e norte da área de estudos. Contudo, nas porções sul e leste, foram registrados os menores valores pluviométricos, com exceção apenas para o ano de 1997, período em que foram registradas as maiores pluviometrias, nas porções sul e norte da área de estudo e nas porções leste e oeste, onde foram quantificados os menores valores.

Diante da série estudada nesses seis (06) anos, notou-se que a pluviometria comportou-se de forma bem variável, de modo que apenas nos ano de 1998 e 1996 a soma da chuva acumulada foi a 2300 a $2350 \mathrm{~mm}$, sendo que, nos demais anos, a soma total ficou sempre abaixo da média estipulada por Tarifa et al. (2006), de 2100 até $2500 \mathrm{~mm}$.

A oscilação das chuvas foi distribuída de forma bem irregular durante este período de estudos, onde em alguns municípios as precipitações pluviométricas foram acentuadas, e em outros, menos expressivas.

Os municípios que tiveram os maiores valores pluviométricos foram Brasnorte, Campos de Júlio, Campo Novo dos Parecis, Comodoro, Juína, Nova Lacerda, Sapezal, e Tangará da Serra. Consequentemente, os menores valores chuvosos estiveram quantificados sobre os municípios de Diamantino, Nova Marilândia, Nova Maringá, Nova Mutum, Santa Rita do Trivelato, São José do Rio Claro e Sorriso.

\section{Referências}

AB'SABER, A. N. Os domínios de natureza no Brasil: potencialidades paisagísticas. Editora Ateliê, São Paulo, SP, 2003.

ASSAD, E. D. \& SANO, E. E. Sistemas de Informações Geográficas: Aplicações na Agricultura, Planaltina, DF, BRASIL/EMBRAPA - Empresa Brasileira de Pesquisas Agropecuárias/Centro de Pesquisas Agropecuárias do Cerrado - CPAC, 1993. 
ASSAD, E. D.; SANO, E. E.; MASUTOMO, R.; CASTRO, L. H. \& SILVA, F. A. M. Veranicos na região dos cerrados brasileiros freqüência e probabilidade de ocorrência. In: Chuva nos Cerrados. ASSAD, E. D. (Coordenador). BRASIL/ EMBRAPA - Empresa Brasileira de Pesquisas Agropecuárias/Centro de Pesquisas Agropecuárias do Cerrado-CPAC, 423 p. Brasília, DF. 1994.

AMARAL, D. L.; FONZAR, B. C. \& OLIVEIRA FILHO, L. C. de. Vegetação. As Regiões Fitoecológicas, sua Natureza e seus Recursos Econômicos. Folha SD.21/Cuiabá. BRASIL/Ministério das Minas e Energia. Projeto RADAMBRASIL, (Levantamento dos Recursos Naturais, 26), p. 401 452, Rio de Janeiro, RJ. 1982.

AYOADE, J. O. 2004. Introdução à climatologia para os trópicos. Ed. Bertrand Brasil, 10ª edição, 332p, Rio de Janeiro, RJ.

BITTENCOURT ROSA, D.; ALVES da SILVA, M.; \& MENEZES LIMA, P. R. As Características Geológicas e Mineralógicas do Granitóide Paranaíta. In: SIMPÓSIO DE GEOLOGIA DO CENTRO OESTE, 6, Cuiabá, MT, UFMT, Anais do., p. 3 - 7, Sociedade Brasileira de Geologia, Núcleo Centro Oeste, Cuiabá, MT. 1997.

BITTENCOURT ROSA, D.; GELA, A.; ALVES, D. de. O.; MACEDO, M.; NASCIMENTO, L. A.; GARCIA NETTO, L. da. R.; PINTO, S. D. S.; BORGES, C. A.; ROSSETO, O. C.; TOCANTINS, N.; LOPES dos SANTOS, P \& GERALDO, A. C. H. Um Estudo Geoambiental Comparativo das Características Morfoestruturais e Morfoesculturais nas Áreas das Bacias do Alto Rio Paraguai e do Rio Teles Pires no Estado de Mato Grosso. Projeto de Pesquisa, Relatório Final Fundação de Amparo à Pesquisa do Estado de Mato Grosso/Conselho Nacional de Desenvolvimento Científico e Tecnológico - FAPEMAT/CNPq, 319 p, Cuiabá, MT. 2002.

CASARIM, D.P.Um estudo observacional sobre os sistemas de bloqueio no hemisfério Sul. In: Chuva nos Cerrados. ASSAD, E. D. (Coordenador), Empresa Brasileira de Pesquisas Agropecuárias - EMBRAPA/Centro de Pesquisas Agropecuárias do Cerrado - CPAC, 423p. Brasília, DF. 1983.

DERBY, O. A. Nota sobre a Geologia e a Paleontologia de Mato Grosso. Archivos do Museu Nacional, (9): 59 - 88, Rio de Janeiro, RJ. 1895.

DURAND-DASTÈS, F. 1968. Climatologie, Encyclopaedia Universalis, 4, p. 618 - 624 .

GARRIDO, W. E.; AZEVEDO. L. G. \& JÚNIOR, M. J. 1982. O clima da região dos cerrados em relação à agricultura. BRASIL/ EMBRAPA - Empresa Brasileira de Pesquisas Agropecuárias/ Centro de Pesquisas Agropecuárias do Cerrado-CPAC, 423 p. Brasília, DF.

EMBRAPA/BRASIL. Empresa Brasileira de Pesquisa Agropecuária. 1999. Sistema Brasileiro de Classificação dos Solos. 429 p, Brasília, DF.

ESTIENNE, P. \& GODARD, A. Climatologie. Armand Colin, Collection U, 365 p, Paris. 1970.

HUGO SILVA, G. H.; LEAL, J. W. L.; SALUM, O. A. L.; DALL'AGNOL, R. \& BASET, M. A. S. Esboço Geológico de Parte da Folha SC/21 - Juruena. In: CONGRESSO BRASILEIRO DE GEOLOGIA, 28, Porto Alegre, RS, Anais do., V. 4, p. 309 - 320, Soc. Bras. Geologia, Porto Alegre, RS. 1974. 
HUGO SILVA, G. H.; LEAL, J. W. L.; MONTALVÃO, R. M. G. de.; BEZERRA, P. E. L.; PIMENTA, O. N. dos.; TASSINARI, C. C. G.\& FERNANDES, C.A.C. Geologia, Folha SC/21 - Juruena. BRASIL. DNPM/MME, Projeto RADAMBRASIL, (Levantamento dos Recursos Naturais, 20), Rio de Janeiro, RJ, p. 21 - 117. 1980.

JURCA, J. \& TOMMASELLI, J. T. G. Contribuição ao zoneamento agroclimático no Estado de São Paulo por meio das classificações climáticas. In: SIMPÓSIO BRASILEIRO DE CLIMATOLOGIA GEOGRÁFICA, V, Curitiba, PR, Cd-rom. 2002.

MATHERON, G. Les variables régionalises et leur estimation. Masson, 305 p, Paris. 1965.

MELO, D. P. \& FRANCO, M. do. S. M. Geomorfologia. Folha SC/21. BRASIL. Departamento Nacional da Produção Mineral. Projeto RADAMBRASIL (Levantamento dos Recursos Naturais, 20), p. 117 - 164, Rio de Janeiro, RJ. 1980.

MONTEIRO, C. A. de F. A Frente Polar Atlântica e as Chuvas de Inverno na Fachada Sul(Oriental do Brasil contribuição metodológica à análise rítmica dos tipos de tempo no Brasil). Série Teses e Monografias, 1, IGEOG/ USP, São Paulo, SP, 69p. 1969.

NIMER, E. Climatologia do Brasil, BRASIL. IBGE, 422 p, Rio de Janeiro, RJ. 1979.

NIMER, E. \& BRANDÃO, A. M. P. M. Balanço hídrico e clima da região dos cerrados. BRASIL. IBGE, 166 p, Rio de Janeiro, RJ. 1989.

SANT'ANNA NETO, J. L. As chuvas no Estado de São Paulo: A variabilidade pluvial nos últimos 100 anos. In: Variabilidade e mudanças climáticas, implicações ambientais e socioeconômicas. SANT'ANNA NETO, J. L. \& ZAVATINI, J. A., (Orgs.) Maringá, PR: Eduem, p. 95 - 112. 2000.

SERRA, A. \& RATISBONNA, L. As massas de ar na América do Sul, Serviço de Meteorologia do Ministério da Agricultura, 59 p, Rio de Janeiro, RJ. 1942.

SERRA, A. Previsão do Tempo. In: Boletim Geográfico, IBGE, Rio de Janeiro, RJ. 1948.

SETTE. D. M. \& TARIFA, J. R. O holorítmo e a gênese dos climas no Mato Grosso- Brasil, In: SIMPÓSIO BRASILEIRO DE CLIMATOLOGIA GEOGRÁFICA, IV, Rio de Janeiro, RJ, Cd-rom. 2000.

SETTE. D. M. Os sistemas atmosféricos de superfície, a circulação secundária e os principais tipos de tempo que atuam no centro do continente sul americano - Mato Grosso - Brasil. In: SIMPÓSIO BRASILEIRO DE CLIMATOLOGIA GEOGRÁFICA, V, Curitiba, PR, Cd-rom. 2002.

SOUSA, R. R.; BITTENCOURT ROSA, D.; NASCIMENTO, L. A. \& LIMA, P. R. M. Estudo da variabilidade pluviométrica no extremo norte do estado de Mato Grosso Entre os anos de 1990 a 1996. Revista Geoambiente On-line, Ano 2006, n. 7, p. 89 - 107, Jataí, GO. 2006.

TARIFA, J. R.; SETTE, D. M.; MADRUGA, L. C. MOREIRA, M. L. C.; ORMOND, G. L.; FILHO, V. D.; SANTOS, J. F. Atlas Climatológico de Mato Grosso: Departamento de Geografia-Universidade Federal de Mato Grosso (UFMT), Cd-rom, Rondonópolis, MT. 2006. 
WERLE, H. J. S. \& ALVES da SILVA, M. Unidades do Relevo de Mato Grosso: Uma Proposta de Classificação. Revista Sociedade \& Natureza, Departamento de Geografia, Universidade Federal de Uberlândia (UFU), Ano 3, n. 15, p. 409 - 415, Uberlândia, MG. 1996.

Romário Rosa de Sousa - mestrando do Programa de pós-graduação em geografia da Universidade Federal de Mato Grosso

Luiz Gonzaga - mestrando do Programa de pós-graduação em geografia da Universidade Federal de Mato Grosso

Doroty Queiroz Topanotti - mestrando do Programa de pós-graduação em geografia da Universidade Federal de Mato Grosso 